\title{
Dynamic and Impure Perovskite Structured Metal Oxide Surfaces
}

\author{
Hansen, Karin Vels; Norrman, Kion; Traulsen, Marie Lund; Mogensen, Mogens Bjerg
}

Published in:

E C S Transactions

Link to article, DOI:

10.1149/08009.0091ecst

Publication date:

2017

Document Version

Peer reviewed version

Link back to DTU Orbit

Citation (APA):

Hansen, K. V., Norrman, K., Traulsen, M. L., \& Mogensen, M. B. (2017). Dynamic and Impure Perovskite Structured Metal Oxide Surfaces. E C S Transactions, 80(9), 91-100. https://doi.org/10.1149/08009.0091ecst

\section{General rights}

Copyright and moral rights for the publications made accessible in the public portal are retained by the authors and/or other copyright owners and it is a condition of accessing publications that users recognise and abide by the legal requirements associated with these rights.

- Users may download and print one copy of any publication from the public portal for the purpose of private study or research.

- You may not further distribute the material or use it for any profit-making activity or commercial gain

- You may freely distribute the URL identifying the publication in the public portal

If you believe that this document breaches copyright please contact us providing details, and we will remove access to the work immediately and investigate your claim. 


\title{
Dynamic and Impure Perovskite Structured Metal Oxide Surfaces
}

\author{
K. V. Hansen, K. Norrman, M. L. Traulsen, and M. B. Mogensen \\ Department of Energy Storage and Conversion, Technical University of Denmark (DTU), \\ Frederiksborgvej 399, DK-4000 Roskilde, Denmark
}

\begin{abstract}
Surfaces of LSF and LSCF perovskite model electrodes were investigated using a variety of analytical methods on flat model electrodes that were prepared as either pellets or as thin films on top of YSZ pellets in other to throw more light on the widely discussed segregation of layers and particles on the electrode surfaces. An experimental test of the suggestion that the segregation might happen in the vacuum in the analysis equipment gave a negative result. Formation of particles containing significant amounts of $\mathrm{S}$ and $\mathrm{Cr}$ from segregation of the trace impurities in the acquired powders were observed, and lead us to a new hypothesis about the differences between flat model electrodes and technical nano-sized composite electrodes.
\end{abstract}

\section{Introduction}

During recent years a lot of results on segregation of metal oxide components to the surfaces of perovskite electrodes for solid oxide cells (SOC) have been published. The electrodes are typically of the families $\left(\mathrm{La}_{1-\mathrm{x}} \mathrm{Sr}_{\mathrm{x}}\right)_{s} \mathrm{MO}_{3}, \mathrm{M}=\mathrm{Mn}, \mathrm{Fe}, \mathrm{Co}$, Ni with $0<\mathrm{x}<1$, and the so-called A/B ratio, usually $0.9<\mathrm{s}<1.1$. M may in principle be a mixture of all four metals, and the mentioned transition metals are only examples. Especially SrO segregations have been reported, but other of the components of the perovskite may also segregate to the surface as well as impurities present in the raw materials. Finally, impurities from surroundings and reactant gases may adsorb to the surface of such electrodes (1-7). Not surprisingly, this has resulted in a big scatter of reported data for measurements of polarization resistance for the electrochemical oxygen exchange measured on model electrodes as illustrated in Fig. 1 (8).

It has been suggested by Yokokawa (9) that the observed SrO segregation is related to the vacuum based ex situ analytical tools such as low energy ion scattering (LEIS), Xray photoelectron spectroscopy (XPS) and time of flight secondary ion mass spectrometry (TOF-SIMS) indicating that the observed segregation forming a thin surface layer might not have happened in atmospheric air at SOC operation temperatures.

As mentioned, the literature results on performance of perovskite based SOC oxygen electrodes are in general quite scattered, so the issue of what is on the perovskite surface, from where it originates, and how and why segregation takes place, is still open for discussion. The aim of this paper is to add some points to this discussion with a main emphasis on impurities as $\mathrm{SiO}_{2}$ in/on the YSZ, and Cr and $\mathrm{S}$ compounds in/on the LSCF perovskite. 


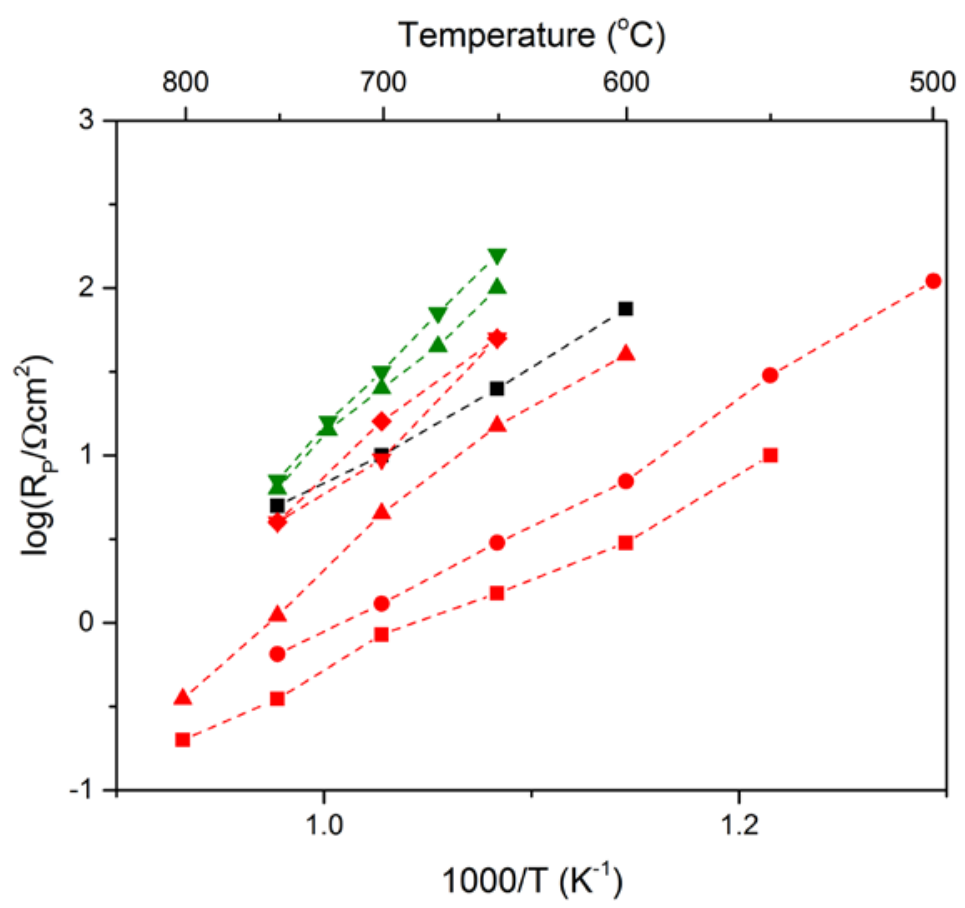

Figure 1. Arrhenius plot of polarization resistance of thin film LSCF electrodes from different sources. Data collected by S. Pitscheider (8) from references (10-12).

\section{Experimental}

Two types of perovskite materials were investigated; one type was in form of a sintered pellet, the other type was in form of thin films and of sintered pellets. The type and degree of segregation from thin surface layers in early stages to $\mu \mathrm{m}$ big surface particles after $200 \mathrm{~h}$ at SOC operation temperatures was studied.

\section{$\underline{\mathrm{LSF}}$}

$\mathrm{La}_{0.6} \mathrm{Sr}_{0.4} \mathrm{FeO}_{3}$ (LSF) powder from Kusaka Rare Metals were pressed to a pellet, sintered for $4 \mathrm{~h}$ at $1300{ }^{\circ} \mathrm{C}$ and polished and cleaned thoroughly. This was used for segregation studies at room temperature in vacuum.

\section{$\underline{\text { LSCF }}$}

$\mathrm{La}_{0.58} \mathrm{Sr}_{0.40} \mathrm{Co}_{0.20} \mathrm{Fe}_{0.80} \mathrm{O}_{3}$ (LSCF) powder from H. C. Stark was used for both types of LSCF samples. The powder was analyzed for impurities by glow discharge mass spectrometry (GDMS). The results are shown in Table 1.

TABLE 1. Impurity content in the $\mathrm{La}_{0.58} \mathrm{Sr}_{0.4} \mathrm{Co}_{0.2} \mathrm{Fe}_{0.8} \mathrm{O}_{3}$ powder of elements above $1 \mathrm{ppm}$ by weight as measured by GDMS in ppm by weight except for $\mathrm{Ca}(*)$, where it is in wt\%.

\begin{tabular}{cccccccccccccccc}
\hline Element & $\mathbf{N a}$ & $\mathbf{M g}$ & $\mathbf{A l}$ & $\mathbf{S i}$ & $\mathbf{P}$ & $\mathbf{S}$ & $\mathbf{C l}$ & $\mathbf{C a}^{*}$ & $\mathbf{T i}$ & $\mathbf{C r}$ & $\mathbf{M n}$ & $\mathbf{N i}$ & $\mathbf{C u}$ & $\mathbf{B a}$ & $\mathbf{H f}$ \\
\hline Conc. & 57 & 95 & 71 & 55 & 27 & 230 & 300 & 0.36 & 13 & 70 & 490 & 63 & 16 & 160 & 9.5 \\
\hline
\end{tabular}




\section{$\underline{\text { LSCF Pellets }}$}

The LSCF powder was used to prepare pellets to study segregation in air. The pellets were pressed and sintered for $12 \mathrm{~h}$ at $1250{ }^{\circ} \mathrm{C}$ and then polished before being heat treated.

\section{$\underline{\text { LSCF Thin Films }}$}

The LSCF powder was used to prepare a target for PLD by pressing and sintering for $2 \mathrm{~h}$ at $1200{ }^{\circ} \mathrm{C}$. Polycrystalline $8 \mathrm{~mol} \%$ yttria-stabilized zirconia (YSZ) (TZ8Y, Tosoh) pellets were prepared for pulsed laser deposition (PLD) of LSCF. The YSZ pellets were pressed and sintered for $2 \mathrm{~h}$ at $1500{ }^{\circ} \mathrm{C}$ and polished, ending with $0.1 \mu \mathrm{m}$ diamond paste and then thoroughly cleaned before deposition. They were $9 \mathrm{~mm}$ in diameter and $1 \mathrm{~mm}$ thick.

LSCF thin films were deposited with a steel shadow mask, producing circular macroelectrodes with a diameter of $5 \mathrm{~mm}$. Thicknesses were measured with a Dektak 3030 Surface Profile Measuring System and were $495 \pm 5 \mathrm{~nm}$. The films were deposited at $650{ }^{\circ} \mathrm{C}$ and with $\mathrm{pO}_{2}=10^{-5}$ mbar with a laser energy of $220 \mathrm{~mJ}$, and a frequency of 30 Hz. Deposition time was 45 min. Figure 2 shows a picture of an LSCF film deposited on a YSZ pellet.

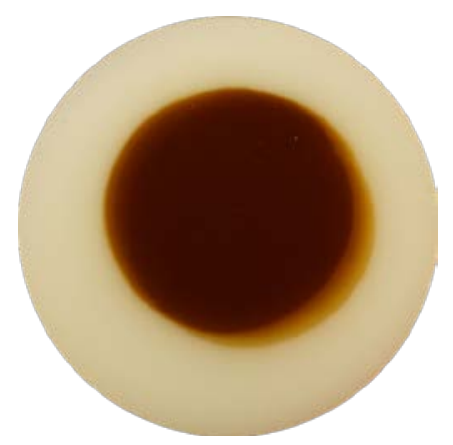

Figure 2. Top view photo of one of the YSZ pellets with LSCF film (S2D). The diameter of the YSZ pellet is $9 \mathrm{~mm}$, and that of the LSCF film is $5 \mathrm{~mm}$. The LSCF thickness is 495 $\pm 5 \mathrm{~nm}$ in the uniform darkest area. The thinner areas are caused by shadow mask drift during deposition.

\section{$\underline{\text { Characterization }}$}

A variety of surface analysis methods were used to characterize either the surface of the pellets and/or the thin films: time-of-flight secondary ion mass spectrometry (TOFSIMS), X-ray photoelectron spectroscopy (XPS), Raman spectroscopy, scanning electron microscopy (SEM) and energy-dispersive X-ray spectroscopy (EDS).

The thin films were characterized after deposition (as-deposited, $45 \mathrm{~min}$. at $650{ }^{\circ} \mathrm{C}$ ), after sintering (as-sintered, $10 \mathrm{~h}$ at $680{ }^{\circ} \mathrm{C}$ ) and after heat treatment $\left(200 \mathrm{~h}\right.$ at $\left.680{ }^{\circ} \mathrm{C}\right)$. Sintering and heat treatment was carried out in synthetic air (pure $\mathrm{N}_{2}+\mathrm{O}_{2}$ ). 


\section{Results and Discussion}

\section{$\underline{\text { Possible Effect of Room Temperature Vacuum on LSF Surface }}$}

In order to clarify the effect of ultra-high vacuum (UHV) on surface segregation, a polished LSF pellet was placed in the XPS chamber $\left(10^{-8} \mathrm{mbar}\right)$ and a depth profile was acquired (Fig. 3a) The depth profile shows that the outermost surface does not show bulk composition. The depth profile was continued until La, $\mathrm{Sr}$ and Fe were constant and this was assumed to be bulk composition and is $\sim 20 \mathrm{~nm}$ below the surface. The surface region down to a depth of ca. $10 \mathrm{~nm}$ is clearly enriched in Sr and depleted in La, while the Fe was not deviating much from the Fe concentration in the bulk. This might be interpreted as the surface region consists of LSF enriched in Sr and depleted La. The sample was left in UHV for $100 \mathrm{~h}$ and then the depth profiling was continued. Both La, Sr and Fe show stable concentrations (Fig. 3b). Within the detection limit of the XPS ( 0.1 atom\%) no measurable Sr- or La-segregation was found during $100 \mathrm{~h}$ in vacuum at room temperature.
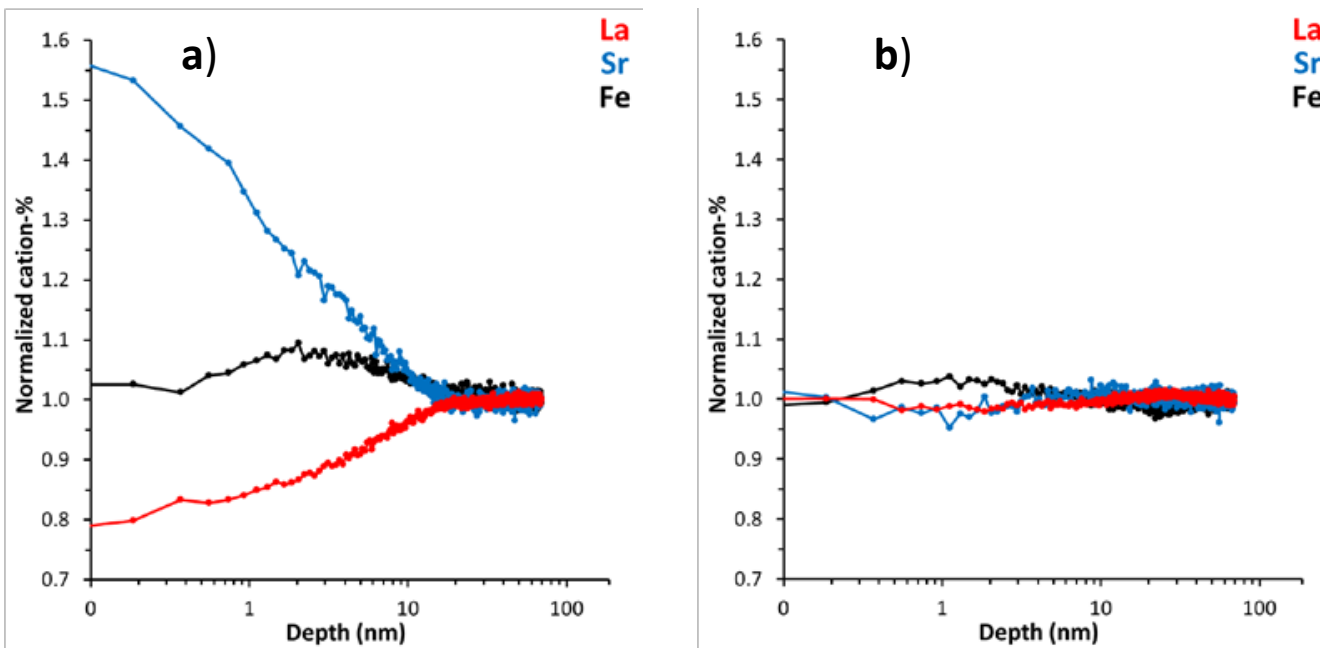

Figure 3. Relative cation concentrations as a function of logarithm of depth from the surface measured by XPS and normalized to the measured concentration at a depth of 75 nm on a $\mathrm{La}_{0.6} \mathrm{Sr}_{0.4} \mathrm{FeO}_{3}$ pellet. a) Depth profile on the as-deposited surface, b) Second depth profile after $100 \mathrm{~h}$ in UHV.

\section{$\underline{\text { LSCF Thin Films on 8YSZ }}$}

The LSCF thin films were deposited on YSZ which has a typical Si content of 10-20 ppm. During sintering the Si segregates to grain boundaries and triple points as imaged in Fig. 4. Other impurities such as $\mathrm{Na}$ and $\mathrm{K}$ show a similar distribution, and this probably means a glassy silicate phase (13). 


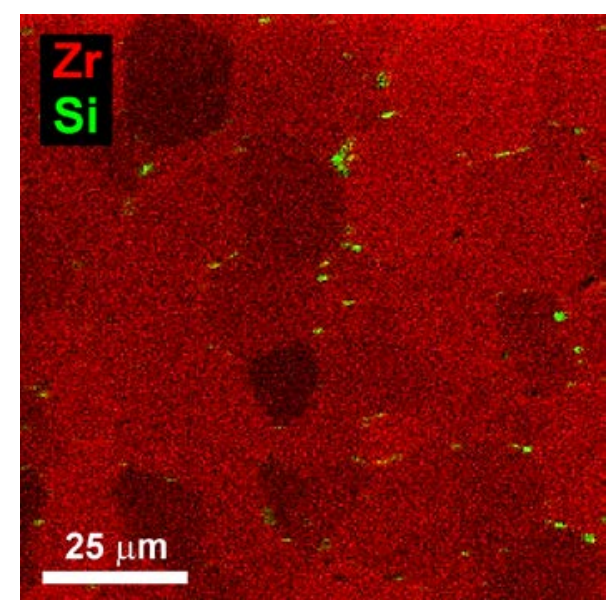

Figure 4. TOF-SIMS composite ion image of the Si and $\mathrm{Zr}$ distribution on the 8YSZ surface away from the as-deposited LSCF macroelectrode.

The LSCF thin films were thoroughly characterized chemically with TOF-SIMS to study the segregation of host and impurity elements to the surface. TOF-SIMS imaging of the entire pellet surface (Fig. 5 and 6) shows that the as-deposited electrode surfaces are free from impurities and contain only host elements. Impurities such as $\mathrm{Na}, \mathrm{K}$, and $\mathrm{Ca}$ are present on the YSZ surface and may originate from the pellet preparation despite the cleaning procedure. During sintering and subsequent heat treatment the segregation of $\mathrm{Sr}$ increases clearly, and La increases significantly in the rim region during the $200 \mathrm{~h}$ heat treatment. Fe, and in particular Co, display decreasing intensity with time while at $680{ }^{\circ} \mathrm{C}$ (Fig. 5).

Fig. 6 shows that the as-deposited film is free from Na, Si and Cr. Si appears on the YSZ surface, and the Cr-content of the film surface increases during the heat treatment. Both observations are supported by XPS measurements. The LSCF powder contains both $\mathrm{Si}$ and $\mathrm{Cr}$ as impurities according to the GDMS analysis. More detailed TOF-SIMS images in Fig. 7 show that the $\mathrm{Cr}$ is not distributed homogeneously on the film surface but it appears in particles together with $\mathrm{Sr}$ and the impurity element, K, but specifically not with La. Further, less intensity of $\mathrm{Na}$ and Fe is seen in the particles than on the rest of the electrode surface.

SEM micrographs of the three differently treated thin films in Fig. 8 confirm that particles appear on the surface of the LSCF during sintering, and that they grow significantly during heat treatment to become laterally micron-sized. 

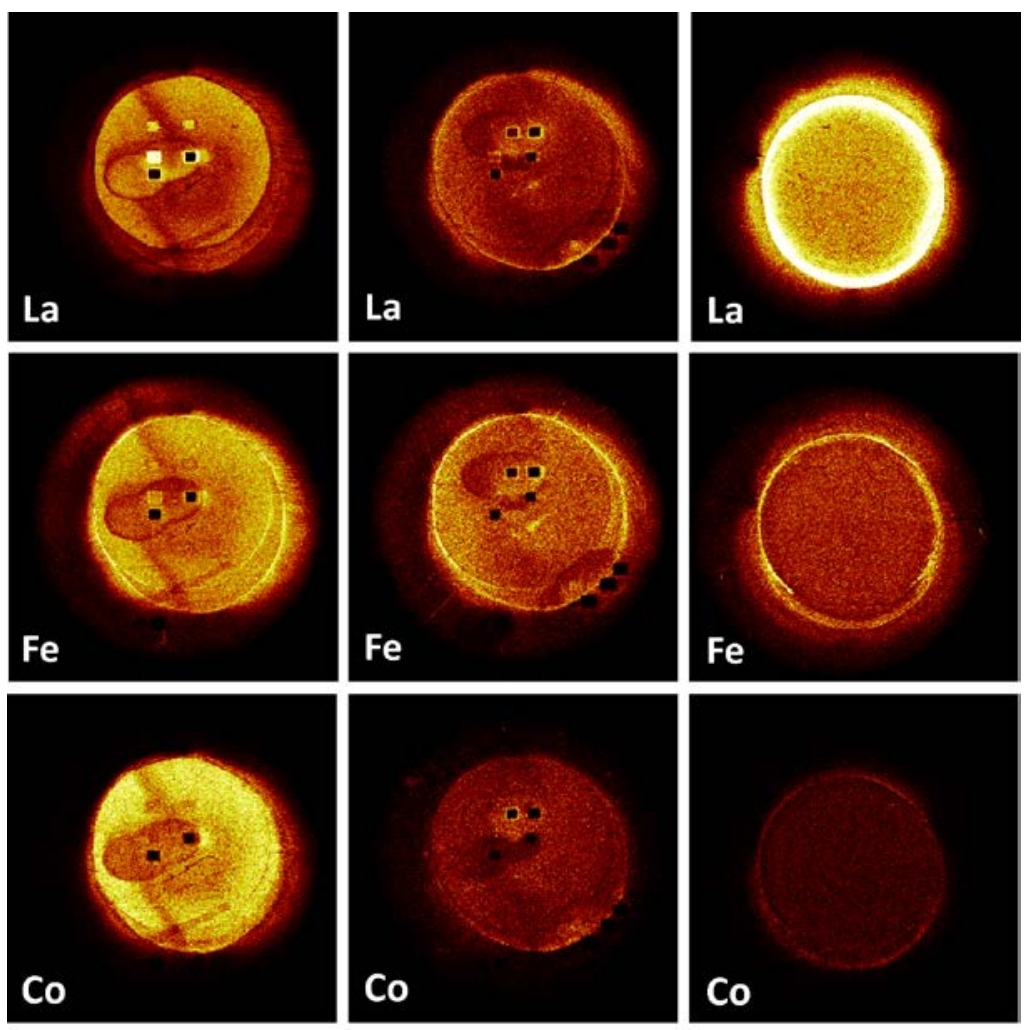

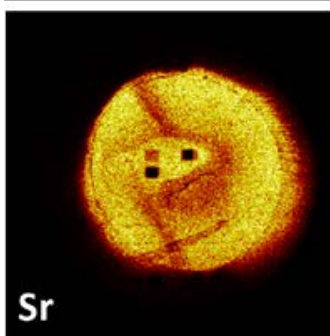

As-deposited

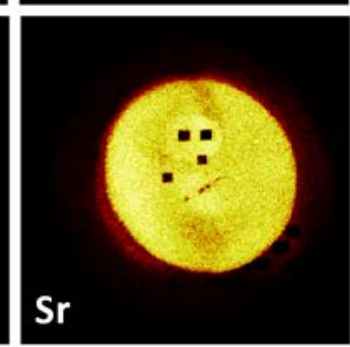

As-sintered

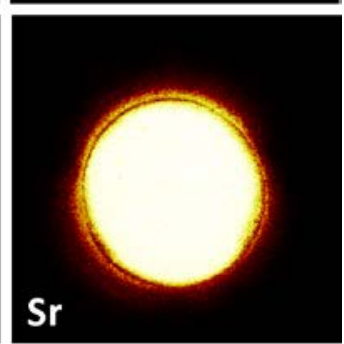

Heat treated

Figure 5. TOF-SIMS ion images $\left(10 \times 10 \mathrm{~mm}^{2}\right)$ of host elements on the entire pellet surfaces with $495 \mathrm{~nm}$ thick LSCF films. The as-deposited and as-sintered $\left(10 \mathrm{~h}, 680^{\circ} \mathrm{C}\right)$ images are from the same sample (S2A), whereas the heat treated sample $\left(200 \mathrm{~h}, 680^{\circ} \mathrm{C}\right)$ is from a nominal identical film (S2D). Tiny squares are craters after depth profiling.

EDS of particles on S2D found ca. $2 \pm 1$ at\% S and ca. $1 \pm 0.6$ at\% $\mathrm{Cr}$ in particles plus the layer beneath them, because EDS has a probing depth of close to $0.5 \mu \mathrm{m}$ at the used conditions. Yet, the electron beam did not penetrate the whole LSCF layer, because no $\mathrm{Zr}$ peak was seen in the EDS spectrum. Thus, the content of S and $\mathrm{Cr}$ in the particles is in reality much higher, and in principle the small particles may consist of $\mathrm{S}$ and $\mathrm{Cr}$ compounds. The ratio of $\mathrm{S}: \mathrm{Cr}$ of ca. 2:1 might be interpreted as formation of particles that have a composition of $\mathrm{SrSO}_{4}$ and $\mathrm{SrCrO}_{4}$ with some $\mathrm{K}$ in solid solution or a $\mathrm{K}$ compound on top of the particles. Fig. 7 reveals that surface areas away from the particles shows increased La and Na ion intensities that might be interpreted as LSCF depleted in Sr and with less than "average" Na impurity in accordance with the EDS measurements. 

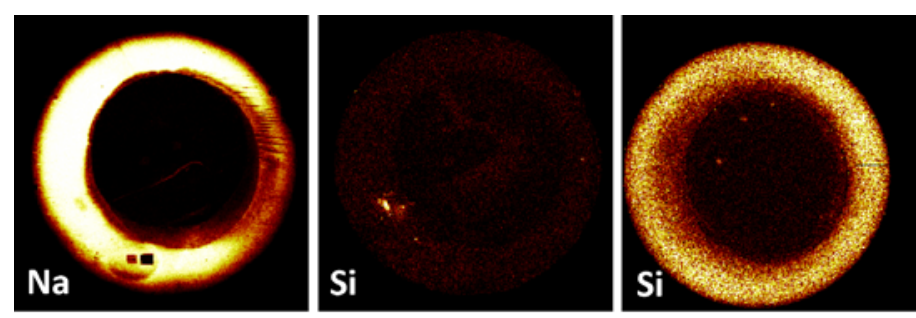

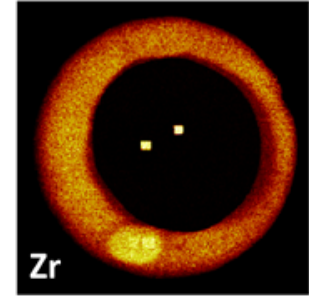

As-deposited

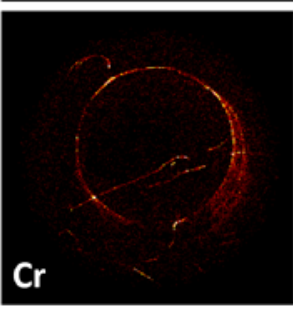

As-deposited

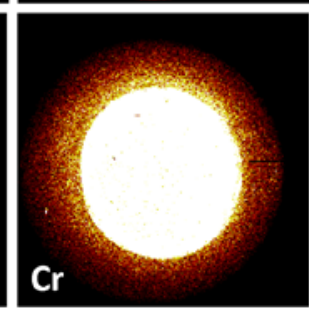

Heat treated

Figure 6. TOF-SIMS ion images $\left(10 \times 10 \mathrm{~mm}^{2}\right)$ of the same LSCF thin films as in Fig. 5. There is essentially no $\mathrm{Na}$ or $\mathrm{Zr}$ (which is only seen in the bottom of the $300 \mu \mathrm{m} \times 300$ $\mu \mathrm{m}$ holes after depth profiling) on the as-deposited electrode surface and minor Si and Cr. On the heat treated thin film Si is present on the YSZ and Cr has segregated to the electrode surface. The intensity in each image is normalized. Thus, the intensities can be compared meaningfully for a given element after different treatments, but intensity changes from one element to another should not be compared.

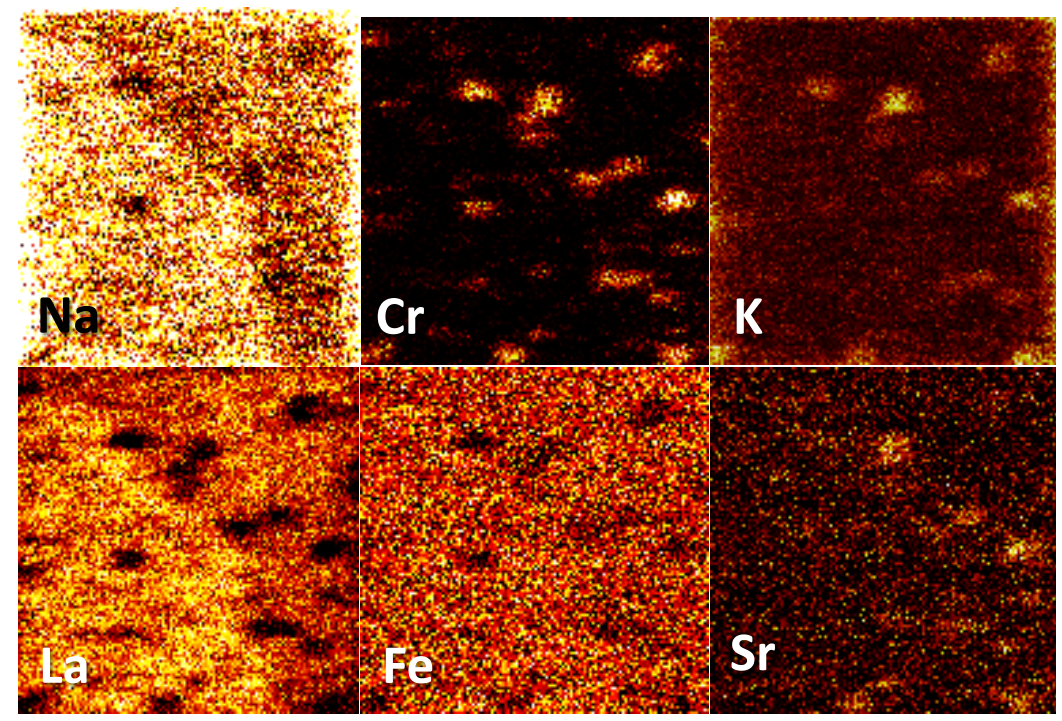

Figure 7. TOF-SIMS ion images $\left(14 \times 14 \mu^{2}\right)$ of a heat treated LSCF surface $(200 \mathrm{~h}$, $680^{\circ} \mathrm{C}$, S2D) showing inhomogeneous surface composition indicating Cr-, K- and Srcontaining particles with little La- and Na-content. The relative weak "shadowing" of Fe by the particles indicate that the particles actually might contain some Fe but less than the surface away from the particles. 

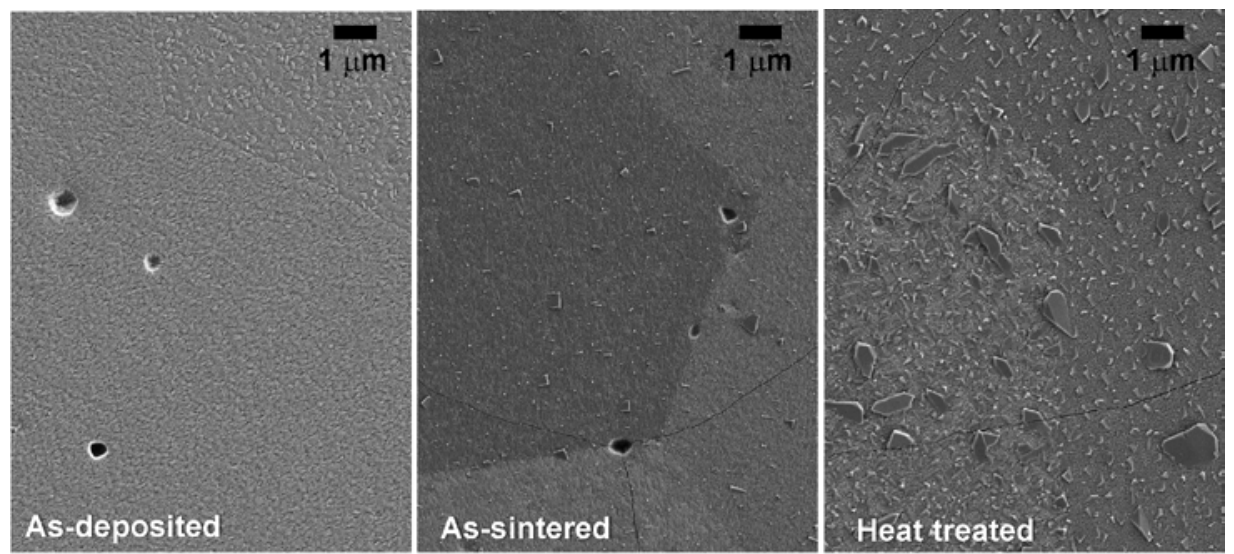

Figure 8. SEM images of the LSCF surfaces of the as-deposited film, after sintering (10 h, $\left.680^{\circ} \mathrm{C}\right)$ and after heat treatment $\left(200 \mathrm{~h}, 680^{\circ} \mathrm{C}\right)$. Cr-containing particles appear during sintering and grow during the subsequent heat treatment.

\section{$\underline{\text { LSCF Pellets }}$}

Sintered LSCF pellets were heat treated at $680^{\circ} \mathrm{C}, 750{ }^{\circ} \mathrm{C}$ and $1000{ }^{\circ} \mathrm{C}$ in synthetic air. In all cases formation of particles on the surface was found as a result of the heat treatment. Raman spectroscopy indicated different compositions depending on the temperature. Fig. 9 shows an example of a Raman spectrum from the pellet heat treated for $200 \mathrm{~h}$ at $750{ }^{\circ} \mathrm{C}$. It is a quite complex spectrum and some possible phases that at least partly could fit the spectrum are shown. SEM reveals that on this sample, particles from nanometer size and up to aggregates of 20-40 $\mu \mathrm{m}$ in diameter had appeared. EDS performed on the same phase showed a simple composition with sulfur, strontium and chromium (Fig. 10). Both strontium sulfate and strontium chromate have been shown to form on LSCF in the presence of external Cr and S sources (14). However, it is important to note here that all samples were heat treated in artificial air made by mixing clean $\mathrm{N}_{2}$ with clean $\mathrm{O}_{2}$. Thus, it seems that the sulfate-chromate particles were formed by segregation of S and Cr impurities, $230 \mathrm{ppm}$ and $70 \mathrm{ppm}$, respectively, in the as-delivered LSCF powder.

The findings here make us put forward the hypothesis that fortunately it will be very difficult to form such segregated surface layers and particles on top of submicron particles of LSCF mixed with CGO in the technical composite oxygen electrodes. In case of the technical composites, sulfate and chromite particles may form inside the composites, but as more or less separate particles. Actually, the activation often seen during the early (from hours to weeks) stage of testing of composite electrode in full cells, might be due to similar processes as those that passivates the surfaces of the thin film model electrodes and pellet surfaces. From similar considerations, we also hypothesize that it will be the more difficult to passivate a model electrode, the thinner it is. 


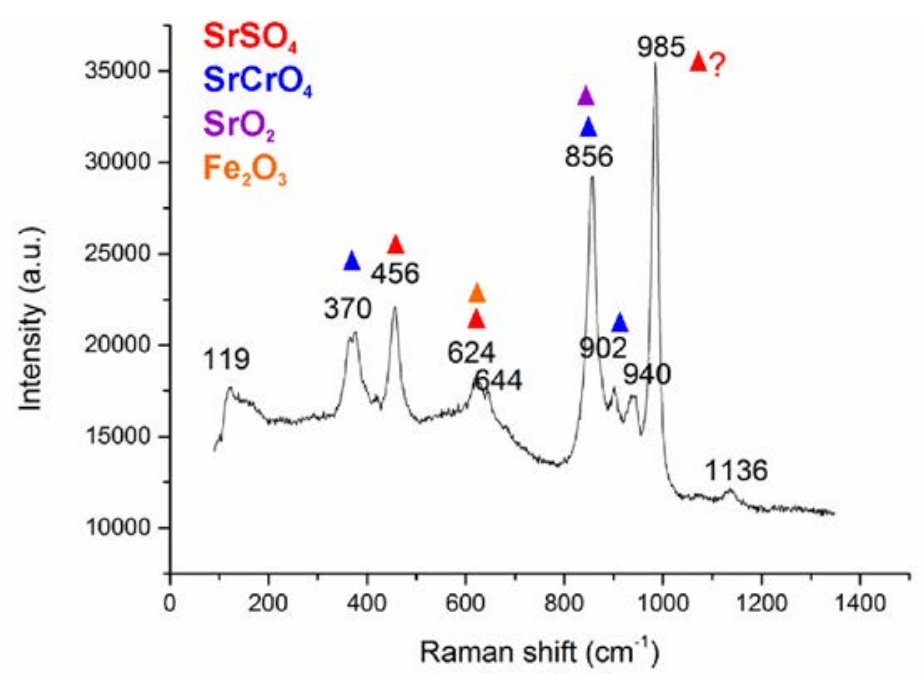

Figure 9. Raman spectrum of the segregated phase on LSCF that was sintered, polished and then heat treated for $200 \mathrm{~h}$ at $750{ }^{\circ} \mathrm{C}$.
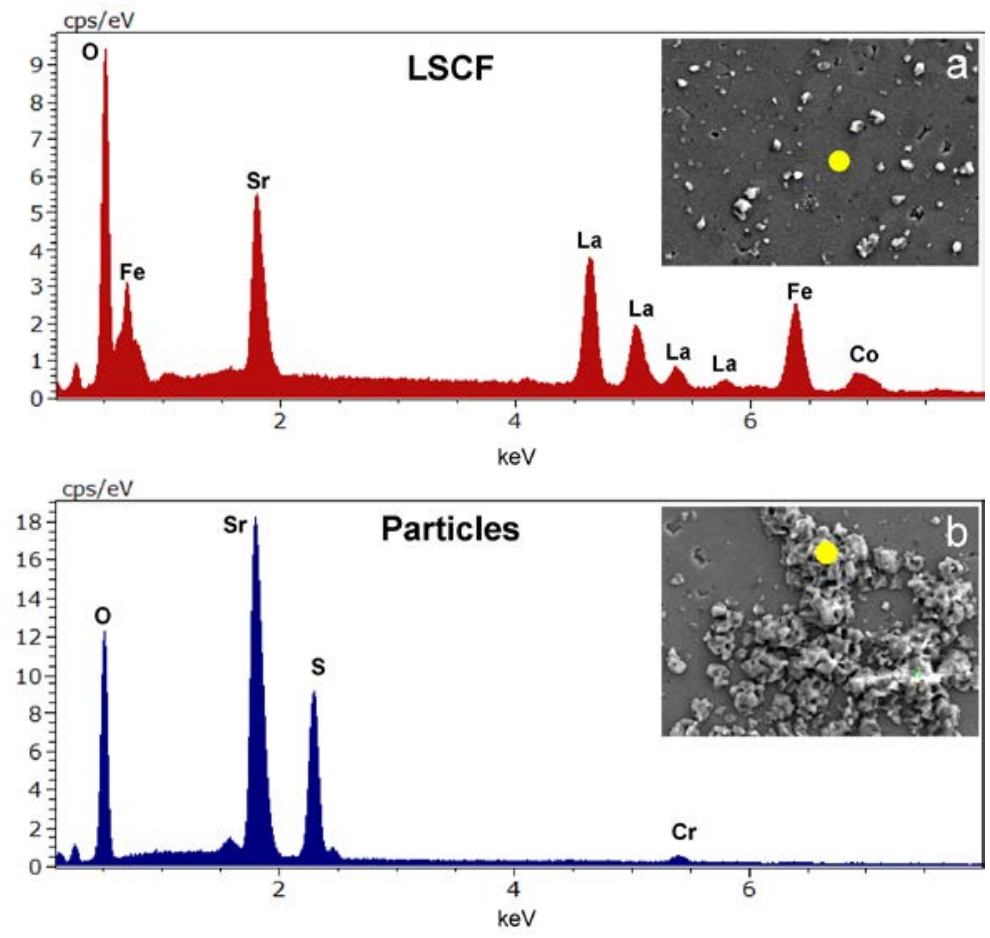

Figure 10. EDS spectra and SEM pictures of a heat treated (200 h at $750{ }^{\circ} \mathrm{C}$ ) LSCF pellet. a) The LSCF surface and b) particles that originates from segregating species.

\section{Conclusion}

LSF and LSFC perovskite surfaces will be covered with segregated $\mathrm{Sr}^{2+}$ and $\mathrm{La}^{3+}$ compounds that partly may consist of impurities originating from the perovskite starting material after relative few hours at $680{ }^{\circ} \mathrm{C}$. Furthermore, the available evidence points to the perovskite surfaces being dynamic with relatively fast changes that are visible within periods of few hours with developments continuing for hundreds of hours. The 
suggestion that segregation of $\mathrm{Sr}^{2+}$ should take place in vacuum at room temperature was not confirmed. The relatively complicated Raman spectrum might indicate that the surface structures are not consisting of well-defined simple crystal compositions, but rather of crystals of mixed $\mathrm{Cr}$ and S impurity oxides. Finally, the results lead us to the hypothesis that the effect of these segregation tendencies on flat surfaces of model electrodes may turn out very differently in the SOC technical nano-composites.

\section{Acknowledgments}

We acknowledge financial support from Energinet.dk through the ForskEL program Solid Oxide Fuel Cells for the Renewable Energy Transition contract no. 2014-1-12231, and by The Energy Technology Development and Demonstration Program (EUDP) at the Danish Energy Agency via project "Maturing SOEC", contract no. 64015-0523. We appreciate the discussions with Professor Robert Walker, Department of Chemistry and Biochemistry, Montana State University, about the interpretation of the Raman spectrum.

\section{References}

1. K. Norrman, K.V. Hansen, T. Jacobsen, RSC Adv., 5, 87679 (2015).

2. F.S. Baumann, J. Fleig, M. Konuma, U. Starke, H.-U. Habermeier, J. Maier, J. Electrochem. Soc., 152, A2074 (2005).

3. J. Druce, H. Tellez, M. Burriel et al., Energy Environ. Sci., 7, 3593 (2014).

4. Z. Cai, Y. Kuru, J. W. Han, Y. Chen, B. Yildiz, J. Am. Chem. Soc., 133, 17696 (2011).

5. H. Tellez, A. Aguadero, J Druce, M. Burriel, S. Fearn, T. Ishihara, D.S. McPhail, J.A. Kilner, J. Anal. At. Spectrom., 29, 136 (2014).

6. J. Druce, H. Téllez, T. Ishihara, J.A. Kilner, ECS Transactions, 68(1) 557 (2015).

7. K.V. Hansen, K. Norrman, T. Jacobsen, Y. Wu, M.B. Mogensen, J. Electrochem. Soc., 162, F1165 (2015).

8. S. Pitscheider et al., to be published

9. Dr. Harumi Yokokawa, Invited Research Scientist, Energy Technology Research Institute, National Institute of Advanced Industrial Science and Technology (AIST), Tsukuba, Japan, Personal communication.

10. F. Baumann J. Fleig, G. Cristiani, B. Stuhlhofer, H.-U. Habermeier, J. Maier, J. Electrochem. Soc., 154, B931 (2007).

11. B.A. Boukamp, N. Hildenbrand, H.J.M. Bouwmeester, D.H.A. Blank, Solid State Ionics, 283, 81 (2015).

12. P. Plonczak M. Søgaard, A. Bieberle-Hütter, P.V. Hendriksen, L.J. Gauckler, J. Electrochem. Soc., 159, B471 (2012).

13. K. V. Hansen, K. Norrman, and M. Mogensen, Surf. Interface Anal., 38, 911 (2006).

14. C.C. Wang, K. Chen, S.P. Jiang, J. Electrochem. Soc., 161, F1133 (2014). 